\title{
The effects of urban impervious surfaces on eco-physiological characteristics of Ginkgo biloba: A case study from Beijing, China
}

\author{
Yingshi Song ${ }^{\mathrm{a}}$, Feng $\mathrm{Li}^{\mathrm{a}, *}$, Xiaoke Wang ${ }^{\mathrm{a}}$, Chongqi $\mathrm{Xu}^{\mathrm{a}}$, Junying Zhang ${ }^{\mathrm{b}}$, Xusheng $\mathrm{Liu}^{\mathrm{c}}$, \\ Hongxing Zhang ${ }^{\mathrm{a}}$ \\ a State Key Laboratory of Urban and Regional Ecology, Research Center for Eco-Environmental Sciences, Chinese Academy of Sciences, 18 Shuangqing Road, \\ Haidian District, Beijing 100085, China \\ ${ }^{\mathrm{b}}$ Institute of Ecology and Biodiversity, School of Life Sciences, Shandong University, Jinan 250100, China \\ ${ }^{c}$ Chinese Academy of Forest Inventory and Planning, State Forestry Administration, 18 Hepingli East Street, Beijing 100714, China
}

\section{A R T I C L E I N F O}

\section{Article history:}

Received 22 July 2014

Received in revised form 10 October 2015

Accepted 12 October 2015

Available online 23 October 2015

\section{Keywords:}

Urban impervious surface

Eco-physiological characteristics

Ginkgo biloba

\begin{abstract}
A B S T R A C T
Accelerated urbanization continues to convert natural lands to impervious surfaces, resulting in serious impacts to the environment, and affecting the growth of urban plants. In this study, we evaluated eight environmental factors, and nine eco-physiological characteristics of Ginkgo biloba planted on two types of impervious surface (totally impervious surface and partly impervious surface), and one non-impervious surface (grass land). Results showed that the primary effect of the impervious surfaces on the environment were increasing air temperature $\left(T_{a}\right)$ and soil temperature $\left(T_{s}\right)$, and decreasing relative humidity of air $(\mathrm{RH})$ and soil moisture content (SMC). G. biloba net photosynthetic rate $\left(P_{n}\right)$ on totally impervious surfaces (TIS), and partly impervious surfaces (PIS) was 39\% and 22\% lower than trees on an urban grass land (GL). $T_{r}$ and $G_{s}$ also showed similar reductions. Compared to GL, $F_{V} / F_{m}$ on TIS and PIS decreased $7 \%$ and $6 \%$, respectively, and $\Phi P S I I$ decreased $32 \%$ and $41 \%$, respectively. Water use efficiency (WUE), light use efficiency (LUE), and $\mathrm{CO}_{2}$ use efficiency (CUE) of G. biloba growing on impervious surfaces were $20-40 \%$ less than those on the grass land. Redundancy analysis (RDA) indicated the combination of environmental factors explained $66 \%$ of the variation of $G$. biloba eco-physiological responses. This study revealed the eco-physiological responses and variation of $G$. biloba to different substrates. Results indicated it is vital to improve plant environmental quality, and enhance urban green ecological services. Our study provides a scientific reference for urban greening, and ecological land construction.
\end{abstract}

(c) 2015 Elsevier GmbH. All rights reserved.

\section{Introduction}

Cities are dominated by anthropogenic activities ( $\mathrm{Su}$ et al., 2010), and a complex social-economic-natural ecosystem (Ma and Wang, 1984). The impervious surface is one of the primary changes imposed by human beings (Elvidge et al., 2007; Nowak and Greenfield, 2012). Driven by the increasing population and urbanization, natural lands have been transformed into anthropogenic impervious surfaces (Hartley et al., 2008), including roads, community squares, roofs (Razzaghmanesh et al., 2014), and

\footnotetext{
* Corresponding author. Tel.: +861062849103.

E-mail addresses: keystone2006@163.com (Y. Song), lifeng@rcees.ac.cn (F. Li), wangxk@rcees.ac.cn (X.Wang),1158589376@qq.com (C.Xu), moonboat1900@163.com(J. Zhang), liuxush@163.com(X. Liu),zhx973@rcees.ac.cn (H. Zhang).
}

parking lots (Burghardt, 2006; Xian et al., 2007). As a result, land without impervious cover is scarce in urban areas. Impervious surfaces provides us with level roads and can seal the soil to prevent the dust from diffusing into the air, but it produces serious impacts to the ecological environment (Schueler, 1994). The most direct effect of impervious surfaces is the urban heat island (Schueler, 1994; Zhao et al., 2011; Zhou and Wang, 2011). Due to thermal properties of impervious surfaces, temperatures in urban areas are higher than suburban areas (Takebayashi and Moriyama, 2009). The other important impact is urban water cycle processes. Most impervious surface materials are typically asphalt, cement, stone, brick, and even plastic, which are waterproof, and have little infiltration. This can increase the surface runoff (Haase and Nuissl, 2007), decrease groundwater recharge (Haase, 2009), and increase the threat of flooding. In addition, impervious surfaces can cut-off the soil-atmosphere gas exchange (Scalenghe and Marsan, 2009). Oxygen gas cannot recharge into 
the soil, and greenhouses gases, such as $\mathrm{CO}_{2}$ and $\mathrm{CH}_{4}$, cannot release into the atmosphere. Impervious surfaces also impact urban plant growth (Zhao et al., 2010; Viswanathan et al., 2011). Scalenghe and Marsan (2009) reported the large impervious surfaces in urban regions leads to a loss in biodiversity. Several studies reported that because of urban heat island, plants flowered earlier in urban relative to rural areas (Roetzer et al., 2000; Neil and $\mathrm{Wu}, 2006)$. However, little research regarding eco-physiological responses of urban plants to impervious surfaces has been performed.

The objectives of this study were to measure the effects of impervious surfaces on photosynthesis and fluorescence of $G$. biloba, and to determine the main driving environmental factors affecting the eco-physiological characteristics of G. biloba in impervious surfaces. We hypothesized impervious surfaces would decrease photosynthetic production and chlorophyll fluorescence.

\section{Materials and methods}

\section{Plant material and experimental design}

The research site was located at Huaqing, in Haidian District, Beijing, China $\left(39^{\circ} 54^{\prime} 20^{\prime \prime} \mathrm{N}, 116^{\circ} 23^{\prime} 29^{\prime \prime} \mathrm{E}\right)$. The experimental design is shown in Fig. 1. Twenty G. biloba trees were measured-TIS (four trees), PIS (eight trees), and GL (eight trees). G. biloba planted on the three treatments were pre-existing mature trees aged 15-17 years with an average height of $7.5 \mathrm{~m}( \pm 1.3)$, average diameter at breast height of $14.5 \mathrm{~cm}( \pm 1.5)$, and average crown of $4.0 \mathrm{~m}( \pm 0.6)$. The totally impervious surface (TIS) was a marble square, approximately $240 \mathrm{~m}^{2}$. The partly impervious surface (PIS) was a brick surface square, approximately $625 \mathrm{~m}^{2}$, and the grass land (GL) was an urban grass area, approximately $340 \mathrm{~m}^{2}$. The distance between TIS and GL is $15 \mathrm{~m}$, and the distance between GL and PIS is $45 \mathrm{~m}$. On the TIS and PIS, G. biloba were planted in a $0.8 \mathrm{~m}^{2}$ pit, and the pit is closed to outside soil and the bottom is impervious, so the trees cannot access soil outside for water and nutrients. On the GL, the trees were planted in the ground directly. All trees were planted 5.0 to $5.5 \mathrm{~m}$ apart.

According to Kong et al. (1998) and Song et al. (2014), the water permeability (WP) of concrete, asphalt and marble surface was nearly $0 \%$, and the water permeability of brick surface was about 33\%, and grass was $88 \%$. During the experimental period, we watered all trees by watering can on the soil surrounding the

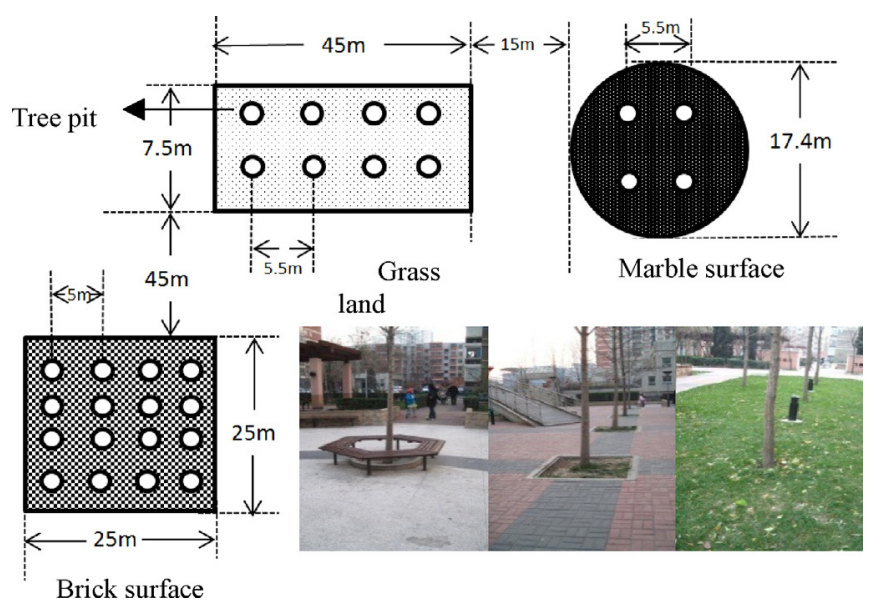

Fig. 1. Sample site distribution. The marble surface represents the totally impervious surface, the brick surface represents the partly impervious surface, and the grass land was the contrast. tree. The trees were irrigated twice a month with 401 applied to the soil around each tree. The soil was not fertilized during the experimental period.

\section{Eco-physiological characteristics measurements}

The Li-6400 portable Photosynthetic System (Li-6400, LiCor, LincoIn, NE, USA) was used to measure photosynthetic gas exchange parameters of $G$. biloba during June to October, 2012. Measurements were conducted once a month. For each Tree 3-5 healthy leaves were selected in facing sun directions at a height of $2.0-2.5 \mathrm{~m}$ for testing. Net photosynthetic rate $\left(P_{n}, \mu \mathrm{mol} \mathrm{CO}_{2} \mathrm{~m}^{-2} \mathrm{~s}^{-1}\right)$, transpiration rate $\left(T_{r}, \mathrm{mmol} \mathrm{H}_{2} \mathrm{O} \mathrm{m}^{-2} \mathrm{~s}^{-1}\right)$, stomatal conductance $\left(G_{s}, \mathrm{~mol} \mathrm{H}_{2} \mathrm{O} \mathrm{m}^{-2} \mathrm{~s}^{-1}\right)$, intercellular $\mathrm{CO}_{2}$ concentration $\left(C_{i}, \mu \mathrm{mol} \mathrm{mol}^{-1}\right)$ and leaf vapor pressure deficit (VPDL, $\mathrm{kPa}$ ) were measured from 9:00 to 11:00 AM on sunny, windless days. After the leaf was tested, we collected the leaf and brought it to the laboratory to calculate fresh and dry weight to test the leaf water content (LWC).

Water use efficiency (WUE), $\mathrm{CO}_{2}$ use efficiency (CUE), and light use efficiency (LUE) were calculated using the following formulas (Long et al., 1993; Nijs et al., 1997; He and Ma, 2000; Yan et al., 2010):

$$
\begin{aligned}
& \text { WUE }=\frac{P_{n}}{T_{r}} \\
& \text { CUE }=\frac{P_{n}}{C_{i}} \\
& \text { LUE }=\frac{P_{n}}{\text { PAR }}
\end{aligned}
$$

where $P_{n}$ is the net photosynthetic rate, $T_{r}$ is the transpiration rate, $C_{i}$ is the intercellular $\mathrm{CO}_{2}$ concentration, PAR is the photosynthetically active radiation.

Chlorophyll fluorescence parameters were measured with a Li6400-40 leaf chamber fluorometer (Li-COR, Inc. USA). We have selected 4 trees for each treatment. And we took 3-5 leaves and averaged to get a single value per tree. The leaves were selected in facing sun directions at a height of $2.0-2.5 \mathrm{~m}$ for testing, within the middle of the crown. Before testing minimum $\left(F_{0}\right)$ and maximum fluorescence $\left(F_{m}\right)$ (Gorbe and Calatayud, 2012), leaves were shaded at least $30 \mathrm{~min} . F_{0}$ was determined under particularly low light, and did not induce variable fluorescence (Yu et al., 2013). $F_{m}$ was determined with a $0.8 \mathrm{~s}$ saturation pulse. Minimum $\left(F_{0}^{\prime}\right)$ and maximum $\left(F_{m}^{\prime}\right)$ light fluorescence were determined on lightadapted leaves, we selected leaves in facing sun directions at a height of $2.0-2.5 \mathrm{~m}$ for testing, within the middle of the crown, but without shaded. And then we measured $F_{0}^{\prime}$ and $F_{m}^{\prime}$. The measurements were similar to $F_{0}$ and $F_{m}$. Steady state yield of PSII fluorescence in the light $\left(F_{S}\right)$ was determined under $600 \mu \mathrm{mol}$ PAR (photons $\mathrm{m}^{-2} \mathrm{~s}^{-1}$ ). The following fluorescence parameters were calculated based on the above measurement: $F_{V} / F_{m}=\left(F_{m}-F_{0}\right) / F_{m}$; $\Phi$ PSII $=\left(F_{m}^{\prime}-F_{s}\right) / F_{m}^{\prime}$; NPQ (Non Photochemical Quenching $)=$ $\left(F_{m}-F_{m}^{\prime}\right) / F_{m}^{\prime}$ (Roháček, 2002).

\section{Environmental factor measurements}

Environmental factors were tested at the same time, when the eco-physiological characteristics measurement. Photosynthetically active radiation (PAR, $\left.\mu \mathrm{mol} \mathrm{m}{ }^{-2} \mathrm{~s}^{-1}\right)$, air temperature $\left(T_{a}\right.$, $\left.{ }^{\circ} \mathrm{C}\right)$, and relative humidity $(\mathrm{RH}, \%)$ were tested by Li-6400 ( $\mathrm{Li}-\mathrm{COR}$, Inc. USA). Soil temperature $\left(T_{s},{ }^{\circ} \mathrm{C}\right)$, soil electric conductivity (EC, $\mathrm{dS} \mathrm{m}^{-1}$ ), and soil volumetric moisture content (SMC, \%) were conducted by $\mathrm{ECH}_{2} \mathrm{O}$ sensor EC-5(Decagon Inc., USA). The probe was inserted into the soil to a depth of $10 \mathrm{~cm}, 50 \mathrm{~cm}$ away from the tree 
stem. For the PIS and TIS testing we measured these parameters in the pit.

\section{Statistical analyses}

Results were analyzed using SPSS software version 18.0 for Windows (Chicago, IL, USA). A Generalized Linear Model was used to analyze of variance among different treatments, and significant differences between different treatments were determined using a LSD multiple range test. Differences were considered statistically significant when $p<0.05$.

Canonical Correlation Analysis (CCA) was conducted on ecophysiological characteristics and environmental factors using Canoco 4.5 software (Lepš and Šmilauer, 2003). Detrended Correspondence Analysis (DCA) showed G. biloba physiological and ecological responses were linear to environmental factors, so the Canonical Redundancy Analysis (RDA) was a applied (Zheng et al., 2011 ) to test relationships between environmental factors (WP, RH, VPDL, $T_{a}, T_{s}$, PAR, EC, and SMC) and physiological and ecological traits $\left(P_{n}, T_{r}, G_{s}, F_{V} / F_{m}\right.$, $\Phi P S I I, N P Q, W U E$, LUE, and CUE). A manual forward selection process was chosen to detect significant factors at $p<0.05$ (Braak and Smilauer, 2002).

We generated $t$-value biplots with CanoDraw software (Lepš and Šmilauer, 2003). $t$-Value biplots was initially used in biology to reveal statistically significant relationships between species and environmental factors. The reason why we used the biplots was that the biplot shows the relationships between dependent variables (arrows) and independent variables (circles). The circle diameter corresponds to the multiple regression coefficient of the dependent and independent variables. The direction and length of the arrow represents the canonical correlation relationship between variables.

\section{Results}

\section{Effects of impervious surfaces on $\mathrm{G}$. biloba's habitat}

Among the six environmental factors, $T_{a}, T_{s}$, RH, and SMC were the four most impacted (Table 1). $T_{a}$ above TIS and PIS was, respectively, 3.22 and $2.07^{\circ} \mathrm{C}$ higher than GL, and there were significant differences between these 3 different treatment $(n=4, p=0.007$, $0.014,0.009$, and 0.01 in June, July, August, and September). $T_{S}$ under TIS and PIS was, respectively, 2.2 and $1.46^{\circ} \mathrm{C}$ higher than GL. The $T_{S}$ of impervious surface (TIS and PIS) was significant higher than $T_{S}$ under GL $(n=4, p=0.047,0.036,0.027$, and $<0.0001$ in June, July, August, and September). Air RH of impervious surface (TIS and PIS) was significant lower than GL $(n=4, p=0.016,0.031,0.0015$, 0.04, and, 0.029 in June, July, August, September, and October); RH above TIS and PIS was, respectively, 6 and 5 (\%) lower than GL. Soil moisture content under impervious surface (TIS and PIS) was significant lower than that under GL $(n=4, p=0.01$ and 0.02 in June and September), and soil moisture content under TIS and PIS was, respectively, $5 \%$ and $4 \%$ lower than GL.

\section{Effects of impervious surfaces on gas exchange characteristics of G. biloba}

During June to October 2012, $P_{n}$ of G. biloba on different surface types showed the following: $P_{n}$ (GL) $>P_{n}$ (PIS) $>P_{n}$ (TIS). $P_{n}$ of $G$. biloba on TIS were significantly lower than those on GL ( $n=4, p=0.001,0.013,0.002,0.041$, and 0.019 in June, July, August, September, and October), but there were no significant difference between TIS and PIS and there were also no significant difference between PIS and GL. $P_{n}$ of G. biloba on TIS and PIS were, respectively $39 \%$ and $22 \%$ lower than those on GL (Fig. 2A). $T_{r}$ of G. biloba on TIS and PIS were, respectively, 30\% and 11\% lower than those on

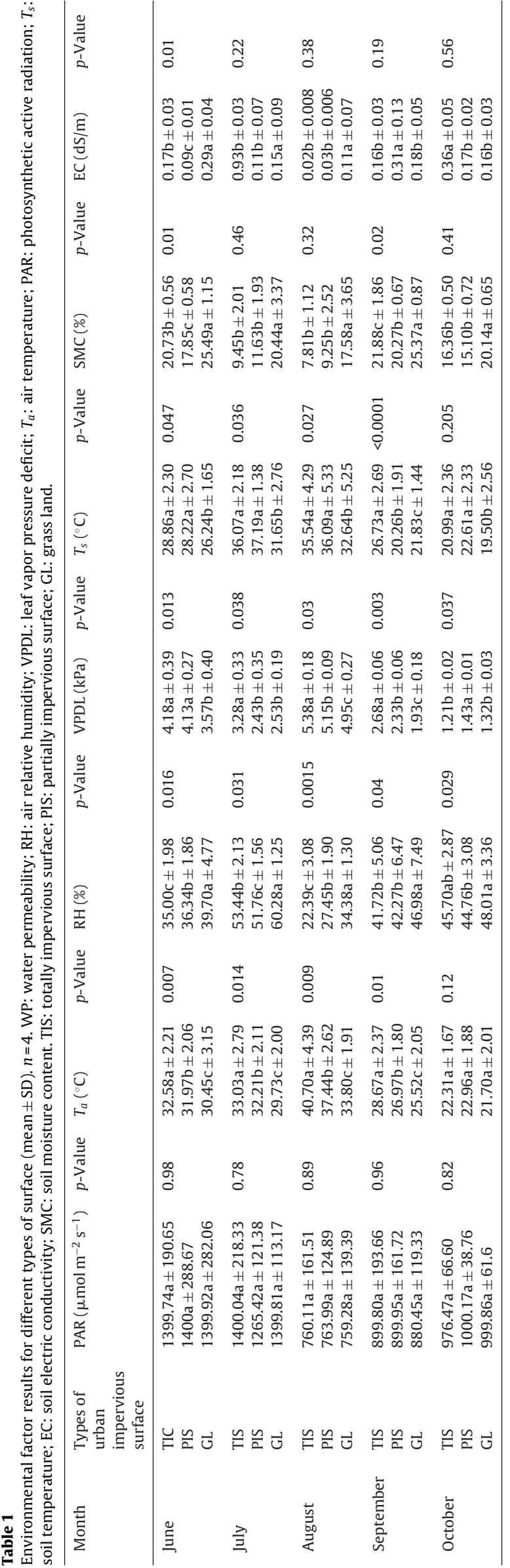



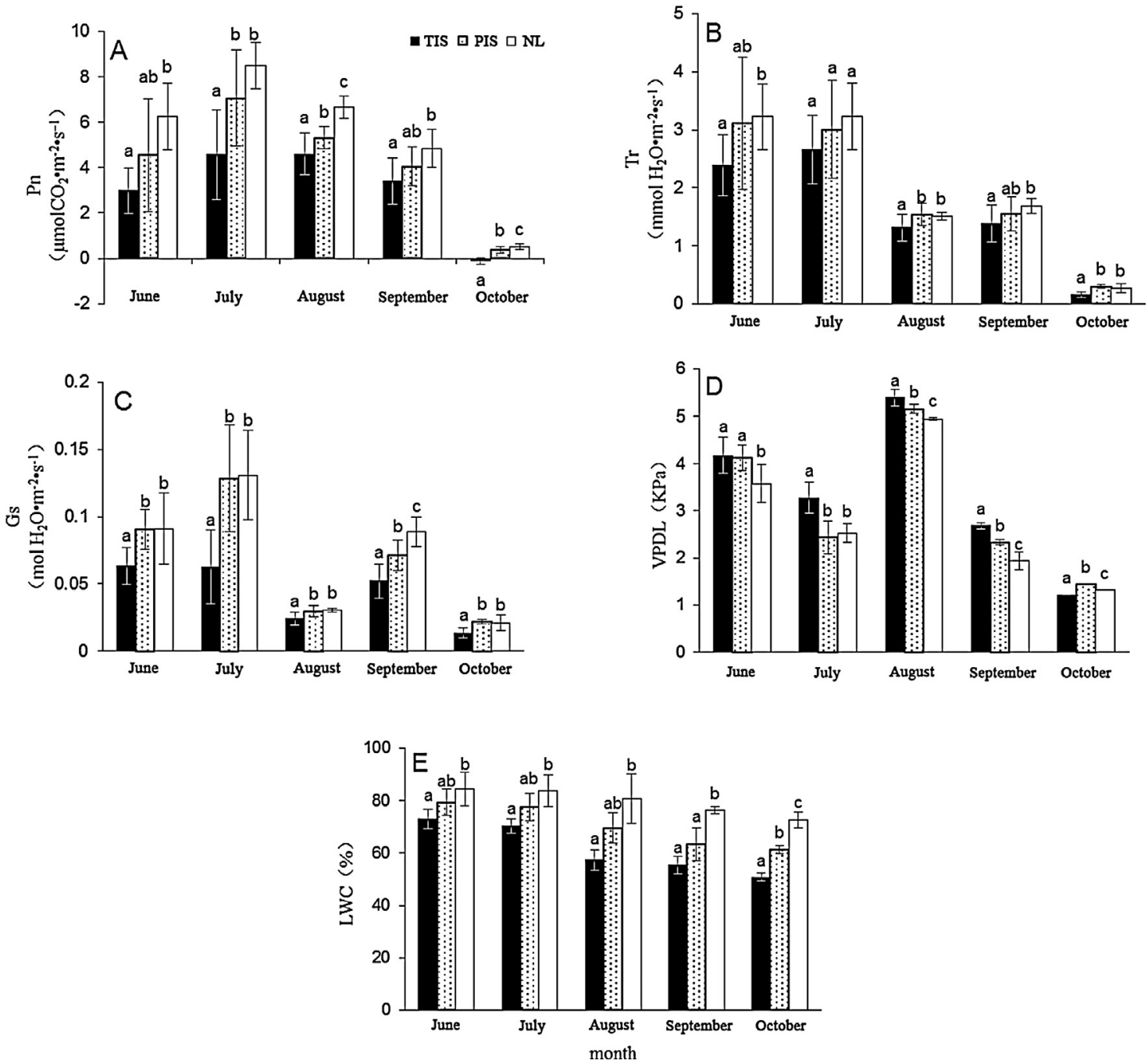

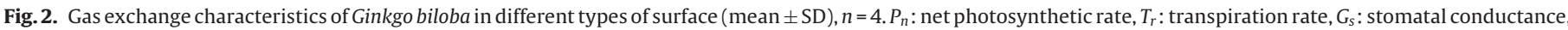
VPDL: leaf vapor pressure deficit; LWC: leaf water content; TIS: Totally impervious surface; PIS: Partially impervious surface; GL: Grass land.

GL (Fig. 2B), but the differences among three treatments were not significant $(n=4, p<0.05)$. $G_{s}$ of $G$. biloba on TIS were significantly lower than those on PIS and GL $(n=4, p=0.009,0.003,0.031,0.001$, and 0.029 in June, July, August, September, and October) (Fig. 2C). The VPDL of $G$. biloba on TIS were significantly higher than those on GL ( $n=4, p=0.029,0.005,0.041,0.001$, and 0.039 in June, July, August, September, and October) (Fig. 2D). From June to October the leaf water content (LWC) of G. biloba on GL was about $80 \%$, however those on TIS and PIS the LWC gradually decreased from $73 \%$ and $79 \%$ to $57 \%$ and $64 \%$, respectively. But only in October there were significant difference among three treatment $(n=4, p=0.005)$ (Fig. 2E).

Effects of impervious surfaces on chlorophyll fluorescence characteristics of $\mathrm{G}$. biloba

$F_{V} / F_{m}$ for $G$. bilola on grass exceeded 0.8 in all months, with the exception of October, but $F_{V} / F_{m}$ on impervious surfaces (TIS and PIS) was below 0.8 from June to October (Fig. 3A). In June, August and October there were significant difference among three treatment $(n=4, p=0.009,0.031,0.001)$. ФPSII of the three surface types were

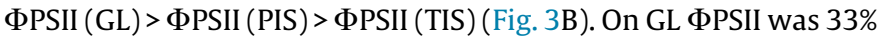
and $19 \%$ higher than TIS and PIS, respectively. In June and July, the
NPQ on impervious surfaces was higher than GL, however inverse results were detected from August to October (Fig. 3C).

\section{The WUE, LUE, and CUE of G. biloba}

WUE of G. biloba on TIS and PIS was, respectively 22\% and 20\% lower than those on GL (Table 2). In August, WUE of G. biloba reached a peak of $4.4,3.46$, and $3.5 \mathrm{mmol} \mathrm{mol}^{-1}$ on GL, PIS, and TIS, respectively. During June to August, the WUE of G. biloba on GL were significantly higher than those on TIS $(n=4, p=0.006,0.025$, and 0.002 ). LUE of G. biloba on GL was $46 \%$ and $21 \%$ higher than that on TIS and PIS (Table 2), LUE of G. biloba on GL were significantly higher than those on TIS ( $n=4, p=0.042,0.001,0.004,0.023$, and 0.001 in June, July, August, September, and October). CUE of G. biloba on GL was $46 \%$ and $25 \%$ higher, than those on TIS and PIS, respectively (Table 2). And in August, the differences of CUE among three treatments were significantly $(n=4, p=0.02)$.

\section{Canonical correlation analysis of environmental factors}

WP, PAR, $T_{a}, \mathrm{RH}, \mathrm{VPDL}, T_{s}$, SMC, and EC were the environmental factors applied as independent variables, and $P_{n}, T_{r}, G_{s}, F_{V} / F_{m}$, ФPSII, NPQ, WUE, LUE, and CUE were the eco-physiological attributes used as dependent variables. RDA results (Table 3 ) showed the 

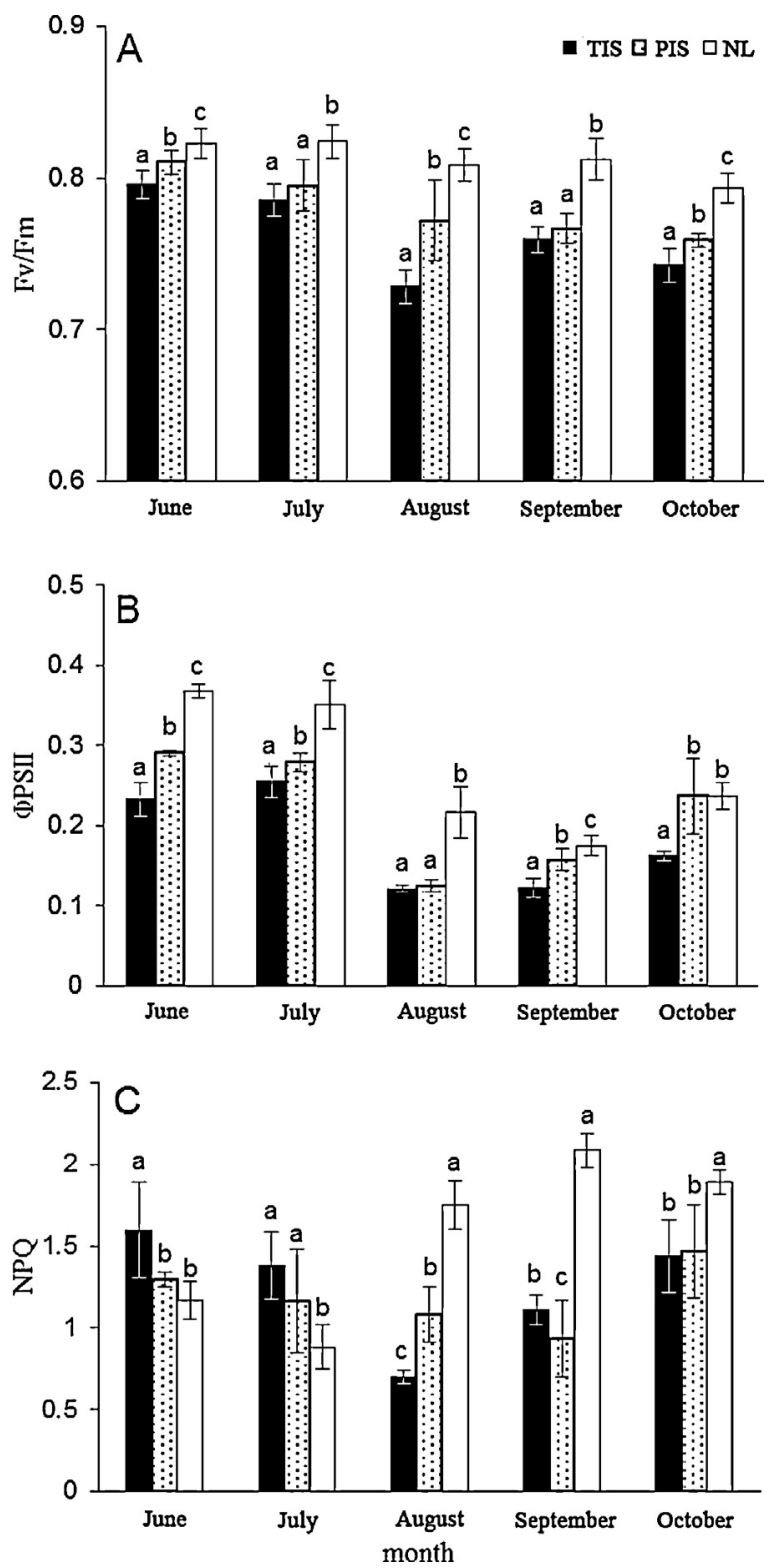

Fig. 3. Chlorophyll fluorescence of Ginkgo biloba on different types of surface (mean $\pm \mathrm{SD}$ ), $n=4 . \quad F_{V} / F_{m}=\left(F_{m}-F_{0}\right) / F_{m}, \quad \Phi$ PSII $=\left(F_{m}^{\prime}-F_{s}\right) / F_{m}^{\prime}$ NPQ (Non Photochemical Quenching) $=\left(F_{m}-F_{m}^{\prime}\right) / F_{m}^{\prime}$. TIS: Totally impervious surface; PIS: Partially impervious surface; GL: Grass land.

eco-physiological indicators for G. biloba were significantly correlated with environmental factors. The correlation coefficient $(r)$ was 0.99 ( $p=0.009)$. The canonical variation included $T_{a}$, VPDL, $\mathrm{RH}, T_{s}$, WP, PAR, and EC, which explained $66.5 \%$ of the total variation of G. biloba eco-physiological indicators. Axis I was correlated with temperature ( $T_{a}$ and $T_{s}$ ), and explained $58.3 \%$ of the total variation in eco-physiological characteristics (Fig. 4); axis II was correlated with RH and VPDL, and accounted for $6.2 \%$ of the total variation; and axis III and IV, respectively accounted for $1.7 \%$ and $0.2 \%$ of the total variation, which was correlated with WP, SMC, and EC. Axis III was positively correlated with $P_{n}(\mathrm{~A}), G_{s}(\mathrm{C})$, $\Phi$ PSII (E), WUE (G), $\operatorname{LUE}(\mathrm{H})$, and CUE (I), which were positively correlated with WP, but negatively correlated with $T_{a}$ and $T_{s}$. While NPQ exhibited a positive correlation with $T_{a}, T_{s}$, and PAR, indicating that high environmental temperature resulted in increased fluorescence and heat dissipation, however energy used for photochemical reactions decreased. $T_{r}(\mathrm{~B})$ and $F_{V} / F_{m}$ (D) were positively correlated with SMC.

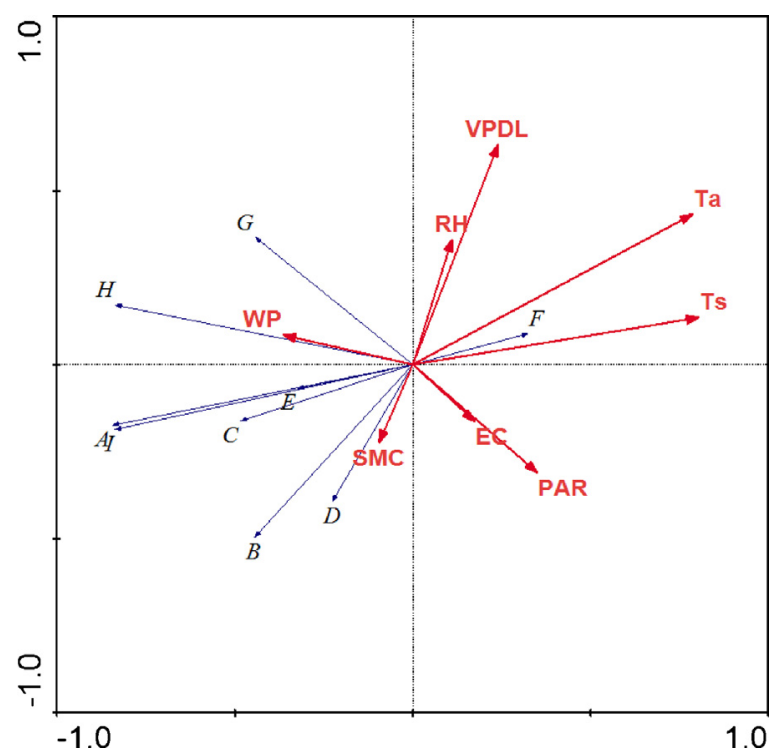

Fig. 4. Redundancy analysis results of eco-physiological characteristics and environmental parameters of Ginkgo biloba. WP: water permeability; RH: air relative humidity; VPDL: leaf vapor pressure deficit; $T_{a}$ : air temperature; PAR: photosynthetic active radiation; $T_{s}$ : soil temperature; EC: soil electric conductivity; SMC: soil moisture content. (A) $P_{n}$, net photosynthetic rate; (B) $T_{r}$, transpiration rate; (C) $G_{s}$,

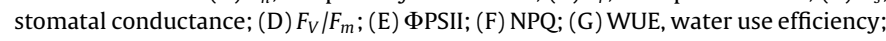
(H) LUE, light use efficiency; (I) $\mathrm{CUE}, \mathrm{CO}_{2}$ use efficiency.

The driving factors of impervious surface on eco-physiological changes

Canoco 4.5 manual selection forward process was used to determine the contribution of every driving factor contributing to eco-physiological changes (Table 4). Results showed, with the exception of SMC, all environmental factors significantly contributed to the eco-physiological variation of $G$. biloba $(p<0.05) . T_{a}$ explained $36 \%$ of the total variation $(p=0.001)$, and VPDL explained $15 \%$ of the total variation $(p=0.001)$. RH was $5 \%$, and $T_{s}$, WP, and PAR were each $3 \%$.

Relationship of the environment and eco-physiological characteristics of $\mathrm{G}$. biloba

A significant negative correlation was detected between $T_{a}$ and $P_{n}, T_{r}$, LUE, CUE $(n=4, p=0.001)$. NPQ showed a positive correlation with $T_{a}$ (Fig. 5a). WUE and LUE exhibited a positive correlation with VPDL, while $P_{n}, T_{r}, F_{V} / F_{m}$, and CUE were negatively correlated with VPDL (Fig. 5b). $P_{n}, T_{r}, F_{V} / F_{m}$, and CUE were all positively correlated with $\mathrm{RH}$, while a negative correlation was detected between WUE, LUE, and RH (Fig. 5c). A significant negative correlation between $T_{s}$ and $P_{n}$, WUE, LUE, CUE was identified ( $\left.n=4, p=0.005\right)$ (Fig. $5 \mathrm{~d}$ ). All characteristics with the exception of NPQ were positively correlated with WP (Fig. 5e). PAR was negatively correlated with WUE and LUE, which might also have an indirect effect on $T_{a}$ (Fig. 5f).

\section{Discussion and conclusion}

Impervious surfaces caused stress in urban plants

Impervious substrates in the urban environment increased air and surface temperatures, reduced air humidity, and soil moisture content during the summer months in Beijing. These changes have previously been report to threatened plant physiological and ecological processes (Zhao et al., 2012). Chlorophyll fluorescence $\left(F_{V} / F_{m}\right)$ reflects the potential quantum efficiency of PSII and is used as a sensitive indicator of plant photosynthetic performance. According to Sarijeva et al. (2007) and Feng et al. (2012) the $F_{V} / F_{m}$ 
Table 2

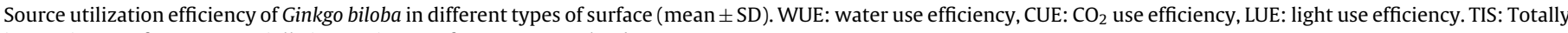
impervious surface. PIS: Partially impervious surface; GL: Grass land.

\begin{tabular}{|c|c|c|c|c|c|c|c|}
\hline Month & $\begin{array}{l}\text { Types of urban } \\
\text { impervious surface }\end{array}$ & WUE $\left(\mathrm{mmol} \mathrm{mol}^{-1}\right)$ & $p$-Value & LUE $\left(\mathrm{mmol} \mathrm{mol}{ }^{-1}\right)$ & $p$-Value & $\mathrm{CUE}\left(\mathrm{mmol} \mathrm{mol}{ }^{-1}\right)$ & $p$-Value \\
\hline June & $\begin{array}{l}\text { TIC } \\
\text { PIS } \\
\text { GL }\end{array}$ & $\begin{array}{l}1.26 a \pm 0.30 \\
1.34 a \pm 0.39 \\
1.93 b \pm 0.16\end{array}$ & 0.006 & $\begin{array}{l}2.13 a \pm 0.71 \\
3.25 a b \pm 1.78 \\
4.46 b \pm 1.04\end{array}$ & 0.042 & $\begin{array}{l}11.06 a \pm 3.77 \\
17.77 a \pm 9.78 \\
25.85 b \pm 5.84\end{array}$ & 0.35 \\
\hline July & $\begin{array}{l}\text { TIS } \\
\text { PIS } \\
\text { GL }\end{array}$ & $\begin{array}{l}1.85 a \pm 0.90 \\
2.31 a b \pm 0.35 \\
2.65 b \pm 0.20\end{array}$ & 0.025 & $\begin{array}{l}3.26 a \pm 1.42 \\
7.27 b \pm 1.76 \\
6.07 b \pm 0.72\end{array}$ & 0.001 & $\begin{array}{l}19.61 a \pm 9.33 \\
25.41 a \pm 7.56 \\
34.44 b \pm 2.56\end{array}$ & 0.29 \\
\hline August & $\begin{array}{l}\text { TIS } \\
\text { PIS } \\
\text { GL }\end{array}$ & $\begin{array}{l}3.50 \mathrm{a} \pm 0.22 \\
3.46 \mathrm{a} \pm 0.16 \\
4.40 \mathrm{~b} \pm 0.33\end{array}$ & 0.002 & $\begin{array}{l}6.05 a \pm 1.19 \\
6.98 b \pm 0.63 \\
8.75 c \pm 0.64\end{array}$ & 0.004 & $\begin{array}{l}16.31 a \pm 3.74 \\
25.29 b \pm 2.19 \\
35.58 c \pm 3.64\end{array}$ & 0.02 \\
\hline September & $\begin{array}{l}\text { TIS } \\
\text { PIS } \\
\text { GL }\end{array}$ & $\begin{array}{l}2.52 a \pm 0.77 \\
2.66 a \pm 0.52 \\
2.88 a \pm 0.54\end{array}$ & 0.79 & $\begin{array}{l}3.77 \mathrm{a} \pm 1.14 \\
4.50 \mathrm{a} \pm 0.95 \\
8.6 \mathrm{~b} \pm 2.08\end{array}$ & 0.023 & $\begin{array}{l}13.24 \mathrm{a} \pm 4.82 \\
14.34 \mathrm{a} \pm 3.59 \\
15.46 \mathrm{a} \pm 3.12\end{array}$ & 0.67 \\
\hline October & $\begin{array}{l}\text { TIS } \\
\text { PIS } \\
\text { GL }\end{array}$ & $\begin{array}{l}- \\
1.20 a \pm 0.34 \\
1.96 a \pm 0.36\end{array}$ & 0.81 & $\begin{array}{l}- \\
0.37 b \pm 0.13 \\
0.51 a \pm 0.12\end{array}$ & 0.001 & $\begin{array}{l}- \\
1.06 \mathrm{~b} \pm 0.39 \\
1.50 \mathrm{a} \pm 0.37\end{array}$ & 0.019 \\
\hline
\end{tabular}

Table 3

Canonical redundancy analysis of eco-physiological characteristics of Ginkgo biloba.

\begin{tabular}{|c|c|c|c|c|}
\hline & \multicolumn{4}{|l|}{ Axis } \\
\hline & $\mathrm{I}$ & II & III & IV \\
\hline Eigenvalues & 0.583 & 0.062 & 0.017 & 0.002 \\
\hline Species-environment correlations & 0.883 & 0.624 & 0.467 & 0.607 \\
\hline Cumulative percentage variance of species data & 58.3 & 64.5 & 66.2 & 66.4 \\
\hline Cumulative percentage variance of species-environment relation & 87.7 & 97.1 & 99.6 & 99.9 \\
\hline Sum of all eigenvalues & \multicolumn{4}{|c|}{1} \\
\hline Sum of all canonical eigenvalues & \multicolumn{4}{|c|}{0.665} \\
\hline
\end{tabular}

is generally above 0.8, Maxwell and Johnson (2000) also found that $F_{V} / F_{m}$, values lower than 0.83 will be seen when the plant has been exposed to stress, indicating in particular the phenomenon of photo inhibition. Zhang (1999) found that the $F_{V} / F_{m}$ is generally above 0.8 , and that variance is minimal. Only under stress, like, being shaded, drought, lack of nutrition, or in extreme temperature, would the $F_{V} / F_{m}$ decrease dramatically. In our study, $F_{V} / F_{m}$ of $G$. biloba on totally impermeable surfaces was below 0.8 during most months, particularly in August, $F_{V} / F_{m}$ decreased to 0.74, indicating leaves were suffering stress conditions.

ФPSII measures the proportion of light absorbed by PSII that is used in photochemistry (Genty et al., 1989; Kitajima and Butler, 1975). High ФPSII means more absorbed energy was used in the photochemistry process. NPQ involves the quenching of single excited state chlorophylls ( $\mathrm{Chl}$ ) via enhanced internal conversion to the ground state (non-radiative decay), thus harmlessly dissipating excess excitation energy as heat through molecular vibrations (Horton and Alexander, 2005). High NPQ means more energy was consumed as heat or for fluorescence dissipation rather than photochemical reactions. Relative to GL treatment, G. biloba on TIS and PIS used less energy in photochemical reactions, but more energy was used for heat dissipation.

Song et al. (2014) found that impervious surfaces decreased $P_{n}$, $T_{r}$, and $G_{s} . P_{n}$ on TIS and PIS were, respectively $39 \%$ and $23 \%$ lower than GL. So the impervious surface has caused a serious impact on G. biloba's carbon uptake and probably leads to lower growth in these plants. There is some previous research about the impact impervious pavement on plant aboveground growth (Morgenroth and Visser, 2011) and root growth (Viswanathan et al., 2011), where results showed that the impervious pavement had a negative effect on plant growth. But there also some conclusion that the impervious surface had increased the root abundance and caused shallow root distribution (Morgenroth, 2011). So the effects of impervious surface on tree growth still needs more experimental studies.

In contrast to unpaved surfaces, the impervious surface increased the soil temperature. Some researchers have drawn similar conclusion, Scalenghe and Marsan (2009) found that impervious surfaces can increase the soil temperature, then temperature of the air close to the surface would be increased. A potential outcome is that the local climate will be modified, leading to urban heat island effect (Takebayashi and Moriyama, 2009; Schueler, 1994; Zhao et al., 2011). Xiao and Weng (2007) revealed that a change in land use toward urban impervious surfaces brought about an increase of air temperature in the Guizhou province.

Impervious surfaces decreased the soil moisture relative to the unpaved surface. This is in contrast to previous research. Morgenroth and Buchan (2009) found that the soil moisture differences are insignificant between pervious and impervious paving,

Table 4

Influence of environmental factors on the eco-physiological characteristics of Ginkgo biloba.

\begin{tabular}{|c|c|c|c|c|c|c|c|c|}
\hline Factors & $T_{a}$ & VPDL & $\mathrm{RH}$ & $T_{S}$ & WP & PAR & EC & SMC \\
\hline Variance explained by the variable (\%) & 36 & 15 & 5 & 3 & 3 & 3 & 1 & 0 \\
\hline$F$-value & 60.91 & 32.20 & 13.44 & 6.48 & 6.53 & 8.54 & 2.92 & 0.20 \\
\hline$p$-Value & 0.001 & 0.001 & 0.001 & 0.005 & 0.002 & 0.001 & 0.009 & 0.893 \\
\hline
\end{tabular}

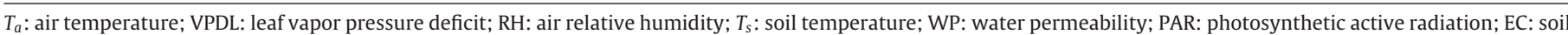
electric conductivity; SMC: soil moisture content. 

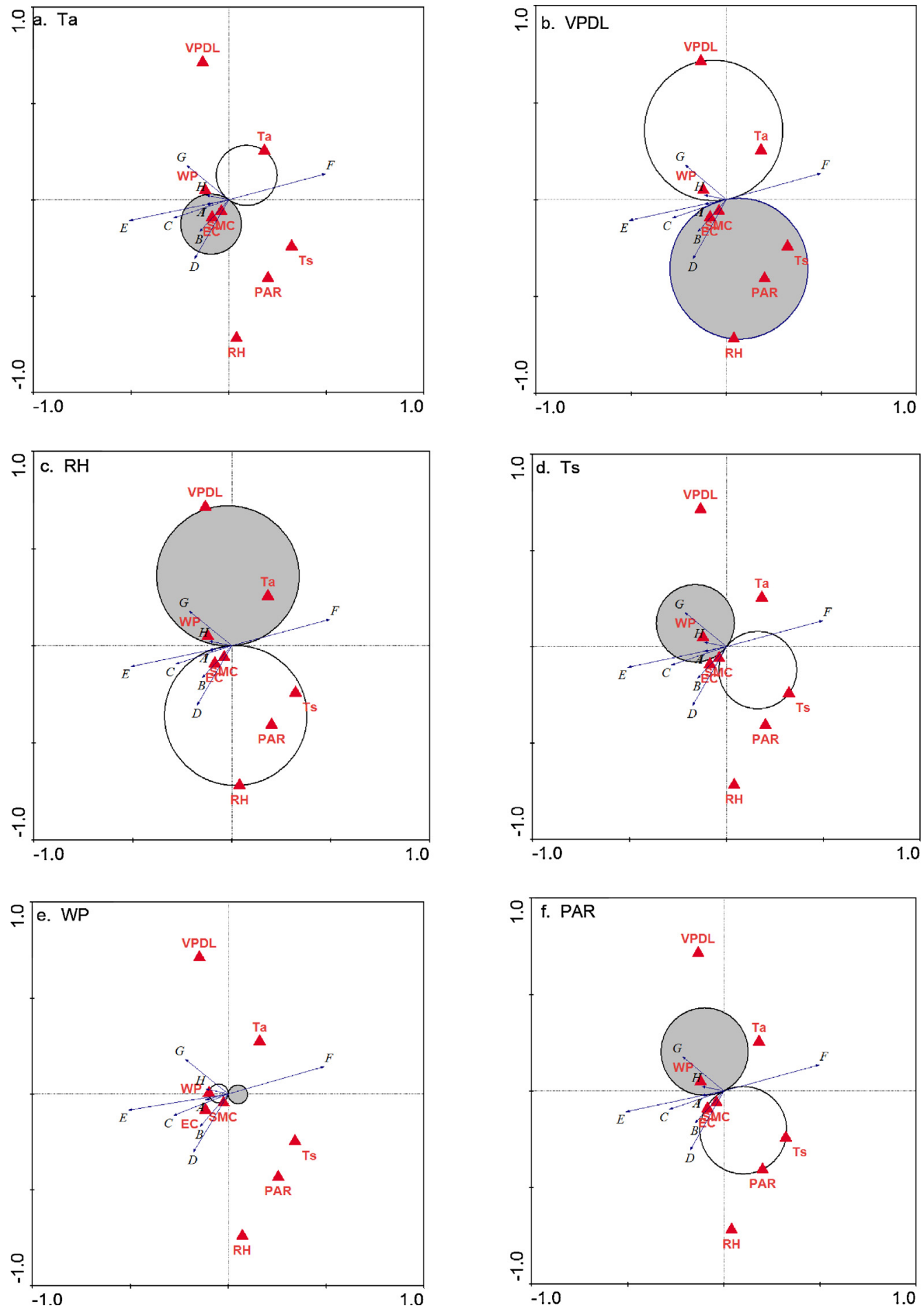

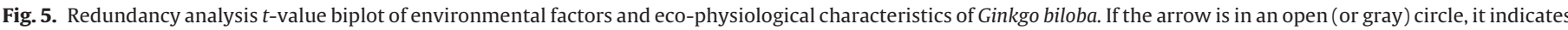

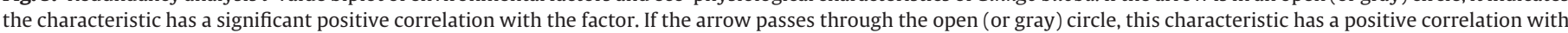

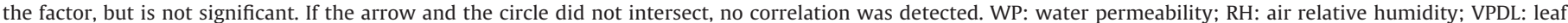

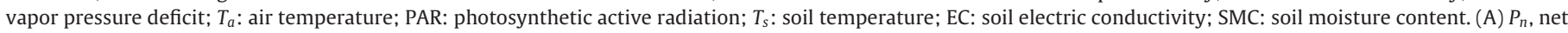

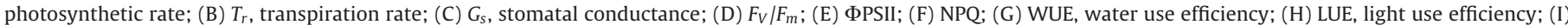
$\mathrm{CUE}, \mathrm{CO}_{2}$ use efficiency.

while other studies have reported that soil moisture is generally greater in soil beneath paved rather than unpaved soil (Morgenroth et al., 2013; Qian et al., 2010). Some other researches have shown that soil moisture is not necessarily lower beneath impervious pavements (Eigenbrod and Kennepohl, 1996; Oh et al., 2010; Hedayati et al., 2014; Grabosky et al., 2009). Clearly more research is needed in this research field.

\section{The main factors affecting $\mathrm{G}$. biloba on impervious surfaces}

The eco-physiological change for G. biloba on impervious surfaces was the result of a series of environmental factor changes. Air temperature is an important factor for photosynthesis; under higher $T_{a}$, net photosynthetic rate was higher, but decreased when $T_{a}$ was higher than $25^{\circ} \mathrm{C}$. VPDL is the water vapor pressure 
difference between the internal leaf and atmosphere (Tan et al., 1978; Hamerlynck, 2001). High VPDL always results in leaf water loss. $P_{n}$ was negatively correlated with VPDL (Islam, 2010). Stomates will close in leaves under heat stress to reduce moisture loss (Farooq et al., 2009), consequently photosynthesis and transpiration is affected. Air RH was also an important factor in leaf physiological processes.

\section{Acknowledgements}

This research was supported by the National Natural Science Foundation of China (nos. 71273254, 30970507). We thank Xiaowen Li for her kind assistance.

\section{References}

Braak, C.t., Smilauer, P., 2002. CANOCO Reference Manual and CanoDraw for Windows User's Guide: Software for Canonical Community Ordination (Version 4.5).

Burghardt, W., 2006. Soil Sealing and Soil Properties Related to Sealing, vol. 266. Geological Society, London, pp. 117-124 (Special Publications).

Eigenbrod, K.D., Kennepohl, G.A., 1996. Moisture accumulation and pore water pressures at base of pavements. Transp. Res. Rec. 1546, 151-161.

Elvidge, C.D., Tuttle, B.T., Sutton, P.C., Baugh, K.E., Howard, A.T., Milesi, C., Bhaduri, B., Nemani, R., 2007. Global distribution and density of constructed impervious surfaces. Sensors 7, 1962-1979.

Farooq, M., Wahid, A., Kobayashi, N., Fujita, D., Basra, S.M.A., 2009. Plant drought stress: effects, mechanisms and management. Agron. Sustainable Dev. 29 (1), $185-212$.

Feng, J.C., Hu, X.L., Mao, X.J., 2012. Application of chlorophyll fluorescence dynamics to plant physiology in adverse circumstance. Econ. For. Res. 20 (4), $14-48$

Genty, B., Briantais, J.M., Baker, N.R., 1989. The relationship between the quantum yield of photosynthetic electron transport and quenching of chlorophyll fluorescence. Biochem. Biophys. Acta 990, 87-92.

Gorbe, E., Calatayud, A., 2012. Applications of chlorophyll fluorescence imaging technique in horticultural research: a review. Sci. Hortic. 138, 24-35.

Grabosky, J., Haffner, E., Bassuk, N., 2009. Plant available moisture in stone-soil media for use under pavement while allowing urban tree root growth. Arboric. Urban For. 35 (5), 271-278.

Haase, D., Nuissl, H., 2007. Does urban sprawl drive changes in the water balance and policy?: The case of Leipzig (Germany) 1870-2003. Landscape Urban Plann. 80, 1-13.

Haase, D., 2009. Effects of urbanisation on the water balance-a long-term trajectory. Environ. Impact Assess. Rev. 29, 211-219.

Hamerlynck, E., 2001. Chlorophyll fluorescence and photosynthetic gas exchange responses to irradiance of Tree of Heaven (Ailanthus altissima) in contrasting urban environments. Photosynthetica 39, 79-86.

Hartley, W., Uffindell, L., Plumb, A., Rawlinson, H.A., Putwain, P., Dickinson, N.M., 2008. Assessing biological indicators for remediated anthropogenic urban soils. Sci. Total Environ. 405, 358-369.

He, W.M., Ma, F.Y., 2000. Effects of water gradient on fluorescence characteristics and gas exchange in Sabina vulgaris seedings. Acta Phytoecol. Sin. 24 (5), 630-634.

Hedayati, M., Hossain, M.S., Mehdibeigi, A., Thian, B., 2014. Real-time modeling of moisture distribution in subgrade soils. Geotech. Spec. Publ. 234, 3015-3024.

Horton, P., Alexander, V.R., 2005. Regulation of photosynthesis under stress: molecular design of the photosystem II light-harvesting antenna: photosynthesis and photoprotection. J. Exp. Bot. 56 (411), 365-373.

Islam, M.T., 2010. Effect of detopping, defoliation and deflowering on photosynthesis and yield parameters of non-branching sesame (Sesamum indicum L.). Int. J. Sustainable Crop Prod. 5 (4), 1-4.

Kitajima, M., Butler, W.L., 1975. Quenching of chlorophyll fluorescence and primary photochemistry in chloroplasts by dibromothymoquinone. Biochim. Biophys. Acta 376, 105-115.

Kong, Z.H., Li, S.R., Li, Y.F., 1998. Effects of different hardened grounds on the material recycling of Platanus acerifolia Willd. Acta Agric. Univ. Henan. 32 (4), 314-319.

Lepš, J., Šmilauer, P., 2003. Multivariate Analysis of Ecological Data using CANOCO. Cambridge University Press, Cambridge.

Long, S.P., Baker, N.R., Rines, C.A., 1993. Analysing the response of photosynthetic $\mathrm{CO} 2$ assimilation to long-term elevation of atmospheric carbon dioxide concentration. Vegetatio 104 (105), 33-45.

Ma, S.J., Wang, R.S., 1984. Social-economic-natural complex ecosystem. Acta Ecol. Sin. $4(1), 1-9$

Maxwell, K., Johnson, G.N., 2000. Chlorophyll fluorescence-a practical guide. J. Exp. Bot. 51 (345), 659-668.
Morgenroth, J., Buchan, G.D., 2009. Soil moisture and aeration beneath pervious and impervious pavements. Arboric. Urban For. 35, 135-141.

Morgenroth, J., Visser, R., 2011. Aboveground growth response of Platanus orientalis to porous pavements. Arboric. Urban For. 37, 1-5.

Morgenroth, J., Buchan, G., Scharenbroch, B.C., 2013. Belowground effects of porous pavements-soil moisture and chemical properties. Ecol. Eng. 51, 221-228.

Morgenroth, J., 2011. Root growth response of Platanus orientalis to porous pavements. Arboric. Urban For. 37, 45-50.

Neil, K., Wu, J., 2006. Effects of urbanization on plant flowering phenology: a review. Urban Ecosyst. 9, 243-257.

Nijs, I., Ferris, R., Blum, H., Hendrey, G., Impens, I., 1997. Stomatal regulation in a changing climate: a field study using free air temperature increase (FATI) and free air $\mathrm{CO}_{2}$ enrichment (FACE). Plant Cell Environ. 20, 1041-1050.

Nowak, D.J., Greenfield, E.J., 2012. Tree and impervious cover change in U.S. cities. Urban For. Urban Green. 11, 21-30.

Oh, J.H., Fernando, E.G., Lee, W., 2010. Consideration of moisture effect on load bearing capacity in Texas flexible pavements. KSCE J. Civ. Eng. 14 (4), 493-501.

Qian, J., Qiu, X., Ling, J., 2010. In-situ testing and evaluation of moisture content in existing sub-grade. Geotech. Spec. Publ. 203, 379-384.

Razzaghmanesh, M., Beecham, S., Kazemi, F., 2014. The growth and survival of plants in urban green roofs in a dry climate. Sci. Total Environ. 476-477, $288-297$.

Roetzer, T. Wittenzeller, M., Haeckel, H., Nekovar, J., 2000. Phenology in central Europe-differences and trends of spring phenophases in urban and rural areas. Int. J. Biometeorol. 44, 60-66.

Roháček, K., 2002. Chlorophyll fluorescence parameters: the definitions, photosynthetic meaning, and mutual relationships. Photosynthetica 40, $13-29$.

Sarijeva, G., Knapp, M., Lichtenthaler, H.K., 2007. Differences in photosynthetic activity, chlorophyll and carotenoid levels, and in chlorophyll fluorescence parameters in green sun and shade leaves of Ginkgo and Fagus. J. Plant Physiol. 164 (7), 950-955.

Scalenghe, R., Marsan, F.A., 2009. The anthropogenic sealing of soils in urban areas. Landscape Urban Plann. 90, 1-10.

Schueler, T.R., 1994. The importance of imperviousness. Watershed Prot. Tech. 1, 100-111.

Song, Y.S., Li, F., Wang, X.K., Fu, Z.H., Zhao, D., 2014. The effects of urban impervious surface on the environment and ecophysiology characteristics of Ginkgo biloba. Acta Ecol. Sin. 34 (8), 2164-2172.

Su, M., Fath, B.D., Yang, Z., 2010. Urban ecosystem health assessment: a review. Sci. Total Environ. 408, 2425-2434.

Takebayashi, H., Moriyama, M., 2009. Study on the urban heat island mitigation effect achieved by converting to grass-covered parking. Sol. Energy 83, 1211-1223.

Tan, C., Black, T., Nnyamah, J., 1978. A simple diffusion model of transpiration applied to a thinned Douglas-fir stand. Ecology 59, 1221-1229.

Viswanathan, B., Volder, A., Watson, W.T., Aitkenhead-Peterson, J.A., 2011. Impervious and pervious pavements increase soil $\mathrm{CO}_{2}$ concentrations and reduce root production of American sweetgum (Liquidambar styraciflua). Urban For. Urban Green. 10 (2), 133-139.

Xian, G., Crane, M., Su, J., 2007. An analysis of urban development and its environmental impact on the Tampa Bay watershed. J. Environ. Manage. 85 965-976.

Xiao, H., Weng, Q., 2007. The impact of land use and land cover changes on land surface temperature in a karst area of China. J. Environ. Manage. 85, 245-257.

Yan, H.L., Zhang, X.M., Xu, H., Liu, Y., 2010. Photosynthetic characteristics responses of three plants to drought stress in Tarim Desert highway shelter belt. Acta Ecol. Sin. 30 (10), 2519-2528.

Yu, C., Huang, S., Hu, X., Deng, W., Xiong, C., Ye, C., Li, Y., Peng, B., 2013. Changes in photosynthesis, chlorophyll fluorescence, and antioxidant enzymes of mulberry (Morus ssp.) in response to salinity and high-temperature stress. Biologia 68, 404-413.

Zhang, S.R., 1999. A discussion on chlorophyll fluorescence kinetics parameters and their significance. Chin. Bull. Bot. 16 (4), 444-448.

Zhao, C., Fu, G., Liu, X., Fu, F., 2011. Urban planning indicators, morphology and climate indicators: a case study for a north-south transect of Beijing, China. Build. Environ. 46, 1174-1183.

Zhao, D., Li, F., Song, Y.S., Ni, H.S., 2012. Relationship between diurnal changes of photosynthesis of Ginkgo biloba and environmental factors under different ground surfaces. Urban Environ. Urban Ecol. 25 (6), 8-12.

Zhao, D., Li, F., Wang, R.S., 2010. Effects of ground surface hardening on plant eco-physiological processes in urban landscapes. Acta Ecol. Sin. 30 (14) 3923-3932.

Zheng, S., Lan, Z., Li, W., Shao, R., Shan, Y., Wan, H., Taube, F., Bai, Y., 2011. Differential responses of plant functional trait to grazing between two contrasting dominant $C_{3}$ and $C_{4}$ species in a typical steppe of Inner Mongolia, China. Plant Soil 340, 141-155

Zhou, X., Wang, Y.C., 2011. Dynamics of land surface temperature in response to land-use/cover change. Geogr. Res. 49, 23-36. 